\title{
Obstacles and Policies of the Social Capital Participates in the Combination of Medical Care and Pension: A Literature Review
}

\author{
Han Qiong \\ Public Administration and Law School, Southwest Jiaotong University, Chengdu, China,.610031.
}

2910382384@qq.com

Keywords: Medical care; Social capital; Review

\begin{abstract}
Under the background of the aging and ageing of the population, encouraging social capital to participate in the combination of medical care and pension is a necessary requirements, which is not only can replenish insufficient healing services provided by the government, but also will improve china's pension security system. The article will review and comb the basic content of the combination of medical care and pension, the obstacles encountered by social capital in participating in it, as well as the policy recommendations. Finally hope to be able to serve a reference for government to formulate relevant social policies, at the same time, provide reference for further theoretical research.
\end{abstract}

\section{Introduction}

According to data from the National Aging Office, there were more than 241 million people aged 60 in china, accounting for $17.3 \%$ of the total population by the end of 2017 . This shows that the aging of the population in china is very serious. And the Fourth National Health Service Survey Report shows that nearly $50 \%$ of the elderly people suffer from various chronic diseases in china, and that elderly people over 65 consume nearly $30 \%$ of the total medical expenses. under such a circumstance, the traditional single old-age pension model has been faced with tremendous pressure and unable to meet the existing pension needs, the demand for the combination of medical care and pension has increased dramatically. Thence, the government has intensively introduced relevant policies to promote the participation of social capital in field of the combination of medical care and pension. such as, In March 2017, the State Council issued the "13th Five-Year Plan for the Development of Old-Aged Careers and the Endowment System", which clearly stated that we must speed up the reform of public pension institutions, support social forces in setting up old-age care institutions; The 19th report proposes to Promote the combination of medical care and pension and support the development of private enterprises. It shows that promotion of the combination of medical care and pension and participation of social capital have become an important task in china. However, according to data released by the National Aging Office, as the end of 2014, only $20 \%$ of them truly have medical service capabilities in the more than 40,000 old-age care institutions in China. The combination of medical care and pension and social capital participation is obviously insufficient and faced with obstacles ${ }^{[14]}$. Therefore, grasp the barriers accurately of social capital participates in it, and then promote social capital participate in the provision of the combination of medical care and pension to Provide efficient medical support for the elderly has become a major livelihood issue.

\section{The Basic Connotation of Medical Care}

Concept of the combination of medical care and pension. Summarize scholars' understanding of the concept of the combination of medical care and pension, it is mainly refers to the organic combination of medical resources and endowment resources in the pension service system, emphasizing Medical and care ${ }^{[1][2]}$, and it is a new type of old-age care that is able to treating illness and Disease-free treatment ${ }^{[3]}$. 
Type the combination of medical care and pension. According to the existing researches, there are two main views on the type of medical care combined pension mode in China. One type is mainly refers: built-in mode, cooperation mode, and community medical care mode ${ }^{[4][5]}$. The built-in model mainly includes internally established medical department in the pension institutions or internally established pension department In the hospital. The other type is that a new institutional model has been added on this basis ${ }^{[6]}$, but most scholars are not frequently reference to the new organization model In the existing study.

The Path of Social Capital Participating in the combination of medical care and pension. According to existing research, there are mainly including two paths of social capital participating in the combination of medical care and pension. The first path is the ppp model that most scholars strongly advocate, they consider that the ppp model which refers public-private-partnership is a effective path to achieve the participation of social capital in the combination of medical care and pension, and in the model, social capital can play a role of just financing, cooperate with various agencies for investment and management and participate in related shares, etc. The other way is that the public-private cooperation can be achieved mainly through business outsourcing, franchising mode, and third-party procurement ${ }^{[7]}$, this is also an alternative effective path.

\section{Obstacles Provided by Social Capital Participating in the Combination of Medical Care and Pension}

It has already been nearly eight years that the State Council has emphasized the development of the combination of medical care and pension in the national policy document for the first time in 2011. However, the supply of medical care combined in our country is obviously insufficient nowadays, and the participation of social capital is not yet in place. This is strongly related to the obstacles encountered in its implementation, it's mainly including following aspects:

Multi-headed management to inefficiency. The integration of the fragmented services of various departments is the core of smooth progress of social capital participate in the combination of medical care and pension. However, in practice, the fragmentation of services is a common occurrence $^{[6]}$, which is mainly caused the following two difficulties: Firstly, the fragmented service causes the social capital Participation is exhausted in responding to the administrative department ${ }^{[8][9]}$. (Wang Puqi, 2018) found that the standards of some departments were not uniform and the procedures were very complicated in the initial period of the social capital participation through his field investigation. Secondly, it's difficult to form a policy joint force to implement policies due to fragmentation of departments. (Huang Jiahao, 2014) found that multi-headed management and no department management coexist in practice through a sample surveys, it is basically difficult to put it in place so that the enthusiasm of social capital is greatly reduced.

Restriction of medical insurance fixed point and medical reimbursement. Whether or not medical and healthcare institutions can be included in the medical insurance fixed point and obtain medical reimbursement is crucial to its own development, but it has encountered many obstacles in reality. Firstly, it is difficult to obtain the qualification for the majority of medical and healthcare institutions, due to their uneven medical equipment and low-level services. Secondly, China's medical insurance currently only reimburses some medical expenses, not including expenses such as nursing and rehabilitation. Thirdly, there is no special insurance for elderly care expenses. such as commercial insurance, long-term care insurance, etc ${ }^{[10-12]}$. under such conditions, a single medical insurance reimbursement is face enormous pressure and its insurance coverage is difficult to expand, this is a realistic dilemma faced by social capital

Access Bar Height. According to research by scholars, the standards of the "medical care and integration" pension institutions have been found to be high and the entry barriers lack flexibility. The current policy stipulates that it must have a second-level or higher hospital qualification and be equipped with five professional doctors and two professional nurses. Organizations with offices above 200 square meters can apply for fixed-point nursing service agencies ${ }^{[12]}$. (Li Jie, 2014) believes that such a one-size-fits-all approach will leave most of the small and medium-sized pension institutions out of the door, affecting the enthusiasm of social capital and making it difficult 
to achieve mutual benefits and complementary advantages.

Talent persons Restrictions. According existed research, the existing number of professional nursing care personnel is far from meeting the actual needs. First of all, the quality of nursing staff is relatively low, and it is difficult to adapt to the needs of the development of socialized old-age care services. At the same time, the cost of nursing staff is high. Besides, the salary of health care workers in medical institutions is low, social identification is not high, and career development prospects are limited. This has a great negative impact on the participation of social capital ${ }^{[12][13]}$.

Unfairness under dual-track system. Although the government has introduced a series of policies to encourage social capital to participate in the provision of medical services, but the benefits are far behind compared with public institutions. Scholars discovered that the government has relatively low financial support for social capital participate in the combination of medical care and pension, However, their responsibility as same as the State-owned institutions. (He Shoukui, 2018) indicate that the government invests less in private healthcare institutions, but it bears same social responsibility and medical price with hospital. It is an institutional barriers to public-private cooperation ${ }^{[14]}$. It's certainly that government policy preferences should be consistent in order to promote the active participation of social capital, otherwise, the enthusiasm of social capital will be greatly frustrated.

\section{Suggestions on Promoting the Participation of Social Capital in Combined Healing Services}

Establish a government-led multi-sector coordination mechanism. The government must fully recognize the positive significance of multi-sectoral coordination mechanisms, Scholars believe that it is possible to promote inter-departmental cooperation by establishing a deliberative coordination body, a joint working conference system, or an administrative coordination mechanism, etc. This beneficial to multi-directional communication and information sharing between departments, accordingly, Improve departmental efficiency and Promote the implementation of various policies $^{[14][15]}$.

Actively publicize the combination of medical care and pension. At present, the public's awareness of the combination of medical care and pension is not high, and it is urgent to increased publicity to change people's traditional thinking and guide people to approve the combination of medical care and pension and encourage more social capital participate in $i^{[13]}$. Specifically, The civil affairs department can provide ideological education to residents through public service advertisements, community lectures, etc. The medical care and pension institution can also pass on its service content to the elderly through the distribution of brochures, etc ${ }^{[15]}$.

Attract talents actively. Promoting preferential policies to attract talents is essential for social capital participates in the combination of medical care and pension development. In the current research, Scholars Suggest that the following aspects can be adopted: First, cooperation with universities, specific measures including provide tuition fee reduction for students who are studying, drop admission policy preferences, sign directional employment agreements, etc. Second, Improve the remuneration system, through social insurance subsidies, post allowances, and increase job attraction. Third, To encourage multi-location practice, support doctors and nurses to shift care services to pension institutions ${ }^{[16]}$.

Innovation grading mechanism of medical care. Building a service sequence according to the different health status and service needs of the elderly is an effective measure to improve service efficiency and quality. On the one hand, this can provide elderly people with a list of pension institutions and their services, so can achieve internal integration of the service system ${ }^{[17]}$. On the other hand, it's beneficial to meet the medical needs of the elderly with different levels of consumption and health conditions, the social capital will have an accurate position on its own service objects and content When it enters medical care and pension ${ }^{[18]}$.

\section{Commentary}

The aging of our country continues to deepen, and the prevalence of chronic diseases in the elderly 
is high. It is difficult for the government to meet the growing demand for pensions. Therefore, encouraging social capital to participate in it becomes an inevitable choice. However, according to existing studies, there is a lack of research on the participation of social capital in the combination of medical services and the provision of services at the current stage. The majority of the research is also mainly focused on the connotation, development model, predicament and countermeasures of the "medical care and support combination" pension model. etc. Through the research of scholars, it is found that the difficulties faced by social capital in participating in the combination of medical care and rehabilitation services are mainly reflected in the unsound system, restricted talents, large project variables, and medical insurance reimbursement. Through research, we must first increase positive publicity and promotion, establish a government-led multi-sector coordination mechanism, promote preferential policies to attract talents, innovate the hierarchical mechanism for medical care, and establish a mechanized information system. Utilize an efficient, easy-to-integrate network to implement the "Internet + Healthcare \& Support" platform

In summary, the study on the participation of social capital in the combination of medical care and support services is still in its infancy. Most of them focus on its connotation, development model, dilemma, and countermeasures, etc., on the operating model and financing of social capital participating in the combination of medical care and support services. There are few studies on path and risk control. Most researches are theoretical analysis of relevant policy documents, and lack of in-depth investigation of actual conditions. Few scholars have demonstrated and analyzed from the perspective of empirical evidence, and they have not extracted the barriers to the participation of social capital in the combination of medical care and support services. Specialized research. In the future, theoretical and empirical researches on the operation mode, financing path, risk control, etc. of the pension provision model provided by social capital in participating in the combined medical and nursing services should be increased in order to promote the active participation of social capital in the service of medical care and support.

\section{Acknowledgements}

This paper is based on work supported by 2018 Social Science Foundation in Chengdu.

\section{References}

[1] W. J. Liu, X. W. Sun .The necessity of constructing the "medical care and support combination" care service model under the perspective of universal health coverage[J].Chinese Health Economics, 2016,35(01):35-37.

[2]J. Li. Research on the "Medicine and Health Care" pension model in Qingdao[J]. China Human Resources Development, 2014(18):74-80.

[3]H. L. Wu. Exploring the practice of medical care and pension support[N]. Fujian Daily, 2013-12-23(011).

[4] J. H. Huang, Q. Meng . The Necessity Dilemma and Countermeasures of the "Medicine and Health Care" Pension Model[J].Chinese Journal of Health Policy,2014,7(06):63-68.

[5] M.Y. ZUO , F. Wang. Problems and Countermeasures Faced by "Combination of Medicine and Health Care"[J]. China Information Society, 2016(02):81-84.

[6] Y. Deng, Z.H. Zhuo. Study on the development of medical and healthcare industry[J].Director of Chinese Hospital,2016(18):54-58

[7]C. L. Mou. PPP model and countermeasures for the development of the combination of medical strength and social strength[J]. Northwest Population, 2018, 39(02): 105-111.

[8]W. C. Wang. Exploration of the "Medicine and Health Care Integration" pension model in Qingdao[J].Journal of Sanitary Software Science,2015,29(02):72-73+77.

[9]X.F. Zhao. Study on "the combination of medical care and health care" in the context of healthy aging[J]. Lanzhou Journal,2014(09):129-136.

[10]D. C. Ruan, Q. C. Peng. Research on the development dilemma and countermeasures of medical care and pension care in China under the "white hair wave"[J].Ningxia Social 
Sciences,2016(04):134-141.

[11] J. F. Chen, S. Wang. Problems and Solutions to the "Medicine and Nutritional Support" Type of the Elderly in Cities: A Case Study of Hefei City[J].Urban Issues,2016(06):92-97.

[12] Y. Wang, Y. Cao. Exploration of the "medical and nursing combination" pension model in Qingdao[J]. Sanitary Soft Science, 2015, 29(02): 72-73+77.

[13] S. Y. Liu. Problems and countermeasures for the development of Beijing medical care and pension support institutions[J].Chinese General Practice Medicine,2016,19(33):4034-4038.

[14] S. K. He. Research on the problems faced by the social capital in participating in the medical care combined project and its governance path [J/OL]. Contemporary Economic Management: 1-11[2018-06-05]. http://kns.cnki.net/kcms/detail /13.1356.F.20180109.2116.011.html.

[15] X. R. Xu, W. H. Zhang. Thinking on the development of medical care and pension support institutions based on social capital theory[J].Chinese Health Service Management,2017,34(08):630-632.

[16]X. J. Zhang. The logic, bottleneck and policy choice of innovation in medical care and pension[J].Northwest China Population,2016,37(01):105-111.

[17]L. L. Ma, N. Chen. Tang Shaoliang. Research on the development policy of endowment service for the medical and healthcare institutions[J].Medical and Society, 2016,29(04):40-43.

[18]C. H. Xu, J. X. Yang. Research on Problems and Countermeasures of the Combination of Medical Care and Pension Support Based on Public Product Theory[J]. Health Economics Research,2015(11):22-24. 